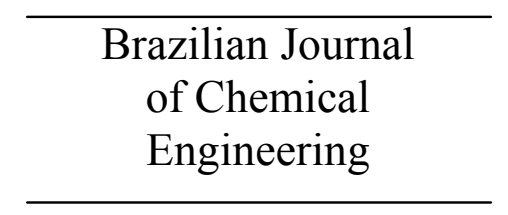

ISSN 0104-6632

Printed in Brazil

www.abeq.org.br/bjche

Vol. 29, No. 01, pp. 1-13, January - March, 2012

\title{
USE OF IONIC LIQUIDS IN BIODIESEL PRODUCTION: A REVIEW
}

\author{
L. Andreani* and J. D. Rocha \\ Embrapa Agroenergia, Parque Estação Biológica, Phone: + (55) (61) 3448-2279, \\ Final da W3 Norte, Asa Norte, CEP: 70770-901, Brasília - DF, Brasil. \\ E-mail: larissa.andreani@embrapa.br
}

(Submitted: July 7, 2011 ; Revised: September 16, 2011 ; Accepted: October 13, 2011)

\begin{abstract}
This paper discusses the feasibility of the use of ionic liquids as catalysts in the biodiesel production field, describing some studies already published in the literature on this theme. Ionic liquids are regarded as a new generation of catalysts in the chemical industry, with several uses in different commercial segments. However only a few publications involving this topic can be found in the literature addressing the manufacture of biodiesel from vegetable oils or animal fats. Through the analysis of the data generated in the studies reviewed, it is possible to affirm that ionic liquids present great potential as catalysts for biodiesel production, but there are some challenges to be faced, such as the production of ionic liquids with low cost, easy recovery and with the possibility of reutilization of the catalyst for several cycles.

Keywords: Ionic liquids; Biodiesel; Catalyst.
\end{abstract}

\section{INTRODUCTION}

This paper reviews studies found in the literature with a focus on the preparation of biodiesel from ionic liquids. The study in the field of ionic liquids began in 1914 with an observation made by Paul Walden, who reported the physical properties of ethylammonium nitrate $\left(\left[\mathrm{EtNH}_{3}\right]\left[\mathrm{NO}_{3}\right]\right)$ (Plechkova and Seddon, 2008). At first, the discovery of ionic liquids did not generate huge excitement. With the occasional exception of some studies in the literature, this issue remained outside the focus of interest of scientists until recently. But in the last decade we have observed a significant increase in the number of studies of the properties and applications of ionic liquids, with many papers published and patents registered. Currently, there are almost 4,000 patents registered involving ionic liquids, with over 3,300 of those registered in the last 5 years and 543 in early 2011, according to the SciFinder database using the search and refinement tools provided in its website (SciFinder, 2011).

Ionic liquids are regarded as a new generation of catalysts in the chemical industry, with potential uses in various commercial segments. The first industrial process involving ionic liquids was announced in March, 2003, by BASF, and is called BASIL (Biphasic Acid Scavenging Using Ionic Liquids). This process generates an ionic liquid in situ to remove $\mathrm{HCl}$ formed during the production of alkoxyphenylphosphines. The resultant alkoxyphenylphosphine is used as an important precursor for the synthesis of photoinitiators used in various industrial processes. The ionic liquid is separated from the product and can be removed by decantation, presenting advantages of cost and easiness compared to filtration (Seddon, 2003). The use of ionic liquids increases the yield of this process by a factor of 80,000 compared to the conventional process (Short, 2006). The reaction is now carried out on a multi-ton scale, proving that ionic liquids can be handled and recycled economically and in large quantities. In addition, BASF has projects in its portfolio such as the use of ionic liquids for breaking azeotropes, replacement of phosgene by $\mathrm{HCl}$ in the chlorination reactions of arenes using ionic liquids as solvents, cellulose dissolution in ionic liquids and their use in aluminium plating (Plechkova and Seddon, 2008).

*To whom correspondence should be addressed 
However, the first company to operate an ionic liquid pilot plant was the French Institute of Petroleum (IFP), which developed a process known as Difasol. This process uses chloroaluminate-based ionic liquids as solvents for nickel catalysts for alkene dimerisation to hexenes and octenes (Plechkova and Seddon, 2008). Other companies are also studying the use of ionic liquids in their processes. Degussa presented a process based on ionic liquids for the synthesis of organosilicon compounds. The use of these salts as solvents allowed easy recyclability and reusability of the catalyst without further treatment after separation of the product at the end of the reaction. ExxonMobil has described a biphasic hydroformylation (a process to obtain aldehydes from alkenes and syngas) with a rhodium catalyst in ionic liquids (Rogers and Seddon, 2003).

This work focuses on studies using ionic liquids as catalysts or supports for processes of esterification and transesterification of vegetable oils and animal fats for producing biodiesel. This topic has been subject of relatively few studies in the literature, with only 133 publications found and, among these, 34 patents (SciFinder, 2011). A demonstration that this is a recent topic of interest is that, of the 133 studies found, 120 were published in the last five years (SciFinder, 2011). Therefore, this area presents an opportunity in the technological domain for pioneering work. The main challenge to be faced in the process is the generation of ionic liquids showing good performance for esterification and transesterification that can be reused several times (if possible, permanently) without yield loss and without the need for laborious purification before reutilization, making this technique a viable process. As immediate advantages, the use of ionic liquids leads to a reduction of the amount of residual water generated in the treatment of biodiesel compared to the traditionally used catalysts and the achievement of processes with fewer steps for product separation and purification.

\section{BIODIESEL PRODUCTION}

The crude oils and fats extracted from vegetable and animal sources are alternatives to the use of highly polluting fossil fuels, but cannot undergo direct combustion in modern diesel engines due to their high viscosity and density (Dupont et al., 2009). These oils are composed of triglycerides that can be converted into biofuels using three main processing techniques: pyrolysis, also known as cracking, microemulsification and transesterification (Ma and Hanna, 1999), which is the most popular method. The oils are also composed, to a lesser extent, by free fatty acids, which can be converted to fatty acid esters by esterification. The alcohols that can be used in the transesterification process are methyl, ethyl, propyl, butyl and amyl alcohols, the most frequently employed being methanol and ethanol. Methanol is widely used due to its low cost in most countries and its physicochemical properties such as polarity and smaller molecular size (Ma and Hanna, 1999). Specifically in Brazil, ethanol has a greater potential of utilization in triglyceride transesterification due to its availability and low toxicity (Dupont et al., 2009). The transesterification reaction produces glycerol as a byproduct, which has various industrial applications.

Figure 1 represents a general scheme for free fatty acid esterification and triglyceride transesterification. As observed, the stoichiometric ratio between alcohol and oil for transesterification is 3:1. However, transesterification of vegetable oils is a reversible reaction, so the reaction yield depends on the shifting of the chemical equilibrium in favor of the esters.

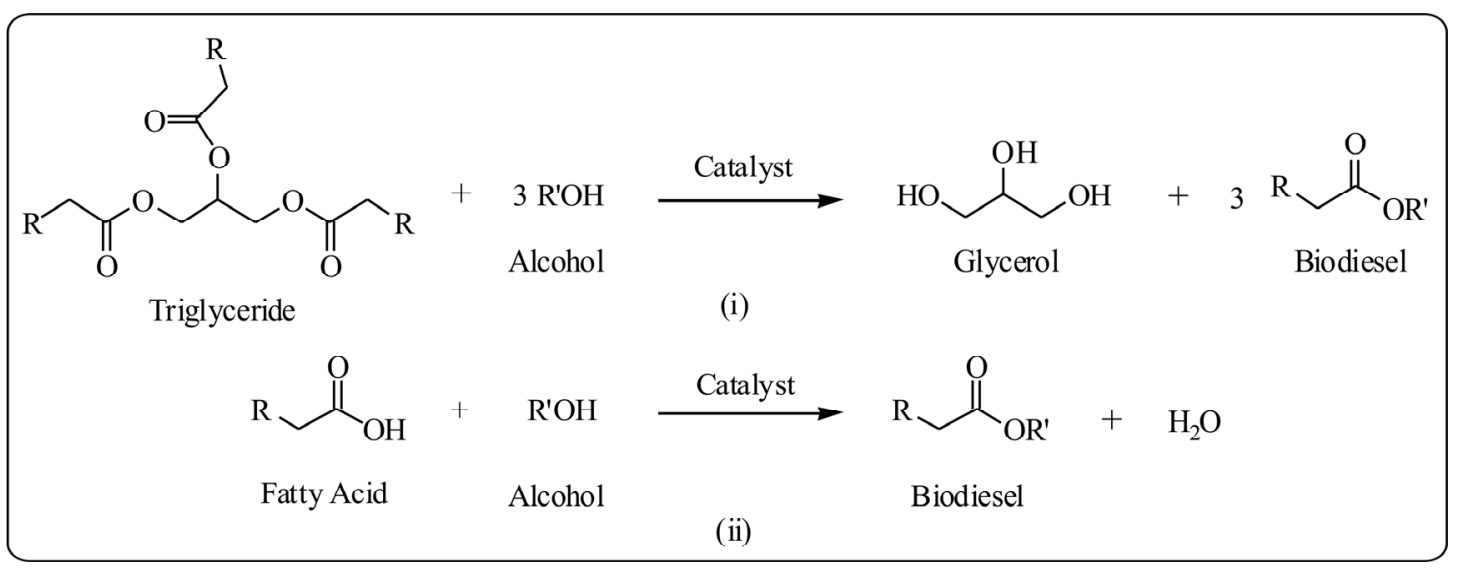

Figure 1: Schematic representation of triglyceride transesterification (i) and free fatty acid esterification (ii). 
Therefore, an excess of alcohol is generally more appropriate to increase the displacement of the equilibrium reaction toward the products (Marchetti et al., 2007). Furthermore, it is necessary to optimize other factors such as catalyst concentration, temperature and agitation of the reaction medium (Gamba et al., 2008). More specifically, the transesterification process is a sequence of three consecutive steps. The first step converts the triglyceride to a diglyceride, the monoglyceride is produced from the diglyceride and, in the last step, glycerol is obtained from the monoglyceride. For effective conversion of oils to biodiesel, the presence of catalysts is usually required.

\section{CATALYSTS IN BIODIESEL PRODUCTION}

There are reports in the literature describing the alcoholysis of vegetable oils or animal fats by a variety of technological routes using several catalysts such as inorganic acids (Dupont et al., 2009; Liang et al., 2009; Zheng et al., 2006), inorganic bases (Dupont et al., 2009; Liang et al., 2009; Vicente et al., 2004) and enzymes (Gamba et al., 2008; Iso et al., 2001; Ranganathan et al., 2008), as discussed below. Depending on the catalyst chosen for the conversion of vegetable oils and animal fats to biodiesel, there are certain peculiarities associated with these reactions. For instance, acid catalysts are especially used when the oil has a high concentration of free fatty acids, with sulfuric and sulfonic acids as the most common catalysts of this class (Dupont et al., 2009). As disadvantages, the acid catalysis requires the use of large amounts of alcohol in order to obtain biodiesel in satisfactory yields, applying molar ratios of alcohol:oil of 30-150:1. Additionally, acid catalysts such as sulfuric acid catalyze the transesterification of triglycerides slowly even when refluxing with methanol, leading to long reaction times such as 48 to 96 hours (Liang et al., 2009). Finally, there is the risk of corrosion of the equipment used due to the high acidity of those catalysts.

The basic (also called alkaline) catalysis is about 4,000 times faster (Dupont et al., 2009) than the acid catalysis and does not require a large quantity of alcohol, often using 6 equivalents of alcohol to 1 of oil. The most commonly used basic catalysts are sodium or potassium hydroxide. Initially, the base reacts with the alcohol, generating its alkoxide, which then reacts with the oil to form biodiesel and glycerol. However, in order to successfully use the base catalysts, the vegetable oils and other reagents used cannot contain water or have high levels of free fatty acid, due to the occurrence of the saponification reaction of triglycerides, leading to unproductive base consumption and rendering the purification of the esters difficult (Dupont et al., 2009). Therefore, the oils used in biodiesel production must be pretreated, making it a time-consuming and costly process. Another disadvantage of this method is the water generated during the reaction of hydroxide ion with the alcohol used, even when water-free reagents are used in the process, leading to the occurrence of saponification. Moreover, the removal of the homogeneous catalysts after the reaction is technically difficult and a large amount of residual wastewater is produced due to separation and purification of products and catalyst (Liang et al., 2009).

An alternative to traditional acidic or alkaline catalysis is the enzymatic process, which overcomes the disadvantages of previous catalytic systems such as equipment corrosion and high energy demands. However, the high cost of enzymes remains a barrier to implementation of the enzymatic process in the industry. Moreover, the presence of alcohols can deactivate and sometimes even denature enzymes. The enzyme activity is also influenced by glycerol. Due to the low solubility of glycerol in biodiesel, a deposit of this byproduct coats the catalyst and thus the activity of the immobilized enzyme is reduced (Gamba et al., 2008).

Due to the disadvantages exposed above, several alternatives that aim to overcome problems encountered with traditional catalysts are currently being researched, as this subject is considered to be a bottleneck in the technology of biodiesel production through transesterification (Dupont et al., 2009). It is possible to find in the literature attempts to produce biodiesel through the use of heterogeneous catalysts (Liu et al., 2008; Puna et al., 2010), organic bases (Schuchardt et al., 1998) and even with no catalyst, using supercritical methanol (He et al., 2007) or supercritical ethanol (Marchetti et al., 2007). Among the alternatives currently under study, the use of ionic liquids in catalytic systems appears to be quite promising and environmentally responsible, because the key to waste minimization in catalytic reactions is the efficient recycling of catalysts (Laus et al., 2005). These ionic liquids can be used to treat byproducts arising from biodiesel production and, in the transesterification of vegetable oils and animal fats, as support for acids or bases, acidic or alkaline catalysts or supported enzymes. 


\section{IONIC LIQUIDS}

\section{Ionic Liquid Characteristics}

Ionic liquids are organic salts composed of anions and cations that are liquid at room temperature, in contrast to the simple inorganic salts that present high melting points. These compounds may be fluid at temperatures as low as $-96^{\circ} \mathrm{C}$ because their ions, although suffering attraction, are relatively large and present a difficult packing, not to mention delocalized charges. However, the ion attraction is sufficient for these compounds to have an almost null vapor pressure, meaning that there is no emission of volatile organic compounds (VOCs) during their use. Moreover, they can be colorless, non-flammable, have high catalytic activity, low viscosity, potential recyclability and are easily manipulated (Plechkova and Seddon, 2008; Seddon, 1997; Earle and Seddon, 2000; Welton, 2004).

The most interesting characteristic of ionic liquids is the possibility of designing a molecule aiming at a specific application or in order to obtain a certain set of properties such as melting point, viscosity, density, water solubility and selectivity (Roosen et al., 2008; Welton, 1999). These compounds also have the ability to dissolve a variety of different substances, including polar and apolar organic compounds, inorganic and polymeric molecules due to their variable structure (Gamba et al., 2008). Ionic liquids present the same interactions found in conventional organic solvents such as hydrogen bonding, dipole-dipole and van der Waals interactions, but also present ionic interactions such as mutual electrostatic attraction or repulsion between charged particles, which makes them very miscible with polar substances. Besides, the cation typically has an alkyl chain, the length of which determines its solubility in apolar fluids (Marsh et al., 2004). Another advantage of these compounds is that there are at least 1 million binary ionic liquids, and $10^{18}$ ternary ionic liquids are potentially possible. In comparison, about 600 molecular solvents are currently in use (Rogers and Seddon, 2003). The ionic liquids give us the opportunity to choose how this compound will act in the reaction medium based on the cation and anion chosen, meaning that the choice of using a particular ionic liquid is conscious, and not random. For these reasons we believe that the use of these salts in industrial green processes is promising provided that efficient recovery, separation of the product and reutilization are possible.

\section{Ionic Liquid Synthesis}

The synthesis of ionic liquids is quite simple and, by controlling the synthesis, it is also possible to control the purity of the materials formed (Plechkova and Seddon, 2008). Ionic liquids composed of the 1- $n$-butyl-3-methylimidazolium cation are the most widely studied and discussed compounds and serve as an example in this section.

A synthetic route for the preparation of these salts starts with alkylation of 1-methylimidazole with a butyl halide, usually a chloride or bromide. 1-methylimidazole is refluxed with excess of butyl halide during 24 hours. This excess is then evaporated and 1-n-butyl-3-methylimidazolium chloride (or bromide) is obtained (Wilkes et al., 1982). The resulting organic salt can be used in three different ways: directly as an ionic liquid; it can be mixed with aluminum chloride or other halometallates, forming chlorometallate-based ionic liquids, widely studied in the literature; or for subsequent metathesis (Holbrey et al., 2002). The metathesis reaction is simply an exchange between cations and anions of the compounds involved. An example is the reaction of 1-n-butyl-3-methylimidazolium chloride with sodium tetrafluoroborate in acetone at room temperature,

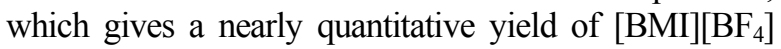
after 24 hours of reaction (Figure 2) (Suarez et al., 1996).

An alternative synthetic route is to prepare alkylsulfonate esters such as butyl methanesulfonate in high yields by treating $n$-butanol with methanesulfonyl chloride in the presence of a base such as triethylamine. Finally, 1-methylimidazole is alkylated with the ester produced in the absence of solvents at room temperature, resulting in the organic salt 1- $n$-butyl-3-methylimidazolium methanesulfonate after 48-72 hours in a nearly quantitative yield. The methanesulfonate anions can be easily replaced by other anions such as $\mathrm{BF}_{4}^{-}$and $\mathrm{PF}_{6}^{-}$through metathesis in aqueous medium at room temperature, presenting yields of 80-95\% (Figure 3) (Cassol et al., 2006).

It is clear that the reactions described here are only examples, and a wide variety of ionic liquids can be prepared following these procedures with slight modifications and varying the anions, cations and alkyl chain lengths of both. The cations are responsible for the physical properties of ionic liquids (such as melting point, viscosity and density), while the anion controls its chemical properties and reactivity (Plechkova and Seddon, 2008). Another factor that may be taken into consideration in the design of an ionic liquid is its hydrophilic/hydrophobic behavior, which affects the solvation properties of ionic liquids. 


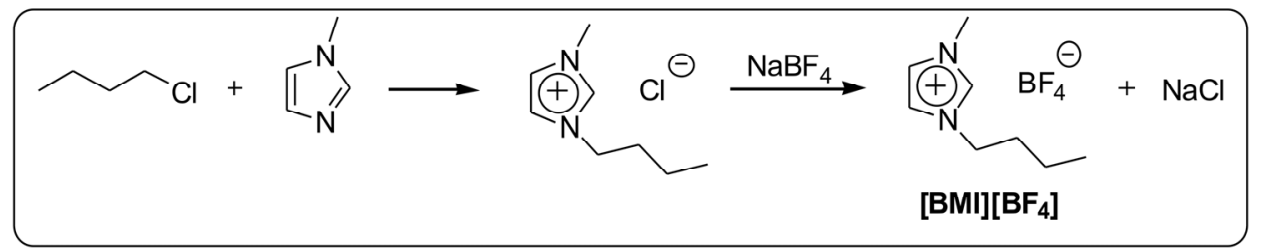

Figure 2: Synthetic route for 1-n-butyl-3-methylimidazolium tetrafluoroborate preparation from 1-methylimidazolium and butyl chloride.

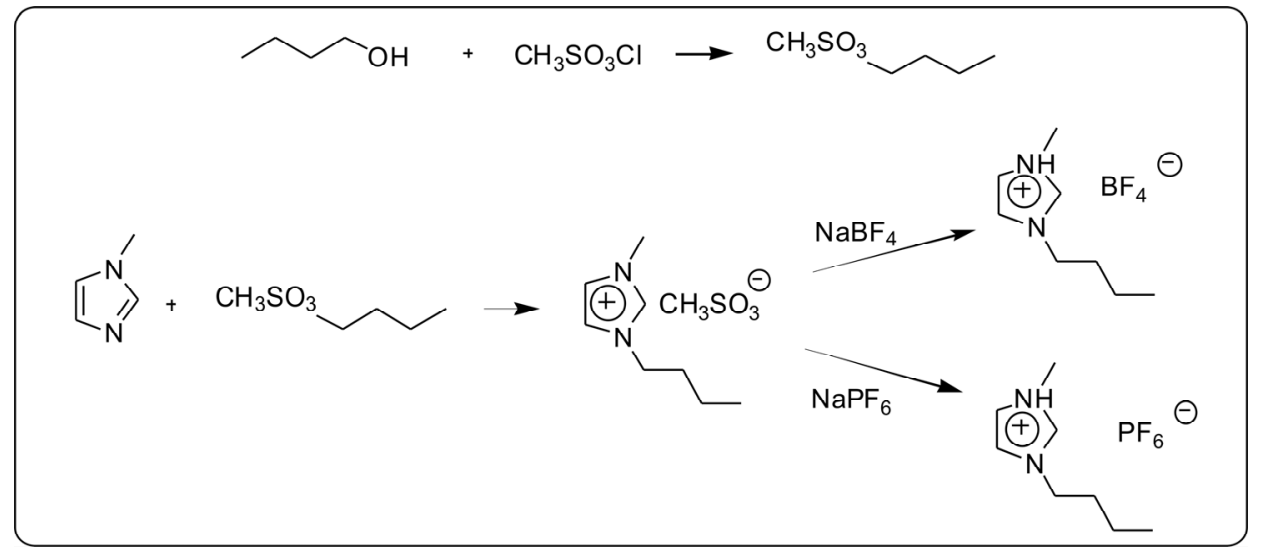

Figure 3: Synthetic route for 1- $n$-butyl-3-methylimidazolium tetrafluoroborate and 1-n-butyl-3-methylimidazolium hexafluorophosphate preparation from $n$-butanol, methanesulfonyl chloride and 1-methylimidazolium.

\section{Ionic Liquids Applications}

Ionic liquids have been used in various fields such as organic synthesis (Forbes et al., 2006), enzymatic catalysis (Rantwijk and Sheldon, 2007), Friedel-Crafts alkylations and acylations (Boon et al., 1986), Diels-Alder cycloaddition (Fischer et al., 1999), aromatic nucleophilic substitutions (D'Anna et al., 2006), spectroscopy and electrochemistry (Anderson et al., 2006), nanomaterials (Li et al., 2008), polymerization (Kubisa, 2009), and extraction and separation processes (Anderson et al., 2006). The most popular ionic liquids are the salts composed of 1,3-dialkylimidazolium cations. The associations of the 1- $n$-butyl-3-methylimidazolium cation (BMI) with bis $\{$ (trifluoromethyl)sulfonyl $\}$ amide $\left(\mathrm{Ntf}_{2}^{-}\right)$, tetrafluoroborate $\left(\mathrm{BF}_{4}^{-}\right)$or hexafluorophosphate $\left(\mathrm{PF}_{6}^{-}\right)$anions (Figure 4) are well studied examples of these salts.

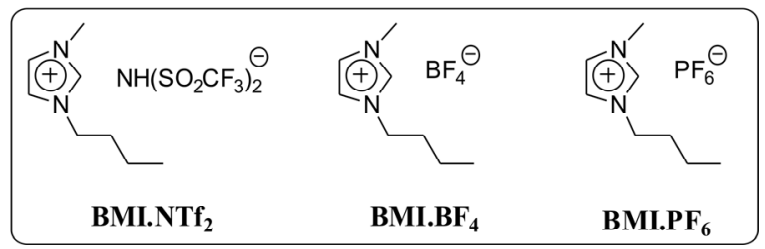

Figure 4: Structures of 1-n-butyl-3-methylimidazolium derived ionic liquids.
An application of ionic liquids in vegetable oil and animal fat processing to biodiesel is reported by $\mathrm{Li}$ and colleagues in 2009 ( $\mathrm{Li}$ et al., 2009a). The authors used the 1-methyl-3-(3-sulfopropil)imidazolium hydrogensulfate ([HSO 3 -PMIM] $\left[\mathrm{HSO}_{4}\right]$ ) ionic liquid to accomplish the esterification of glycerol with acetic acid, forming glycerol triacetate, a substance used in various industry sectors, such as cigarettes production, food and flavouring production, prints and dyes. The conversion using the ionic liquid catalyst led to $95 \%$ yield and, even after the reuse of this catalyst 10 times, the yield of glycerol triacetate remained above 91\%. Ionic liquids were also been used as support for $\pi$-complexing sorbents for extraction of methyl linolenate (18:3) present in biodiesel made from soybean oil. Pi-complexing sorbents such as silver salts form reversible $\pi$-bonded complexes with double bonds. The use of a solid support where silver salts can be firmly anchored allows recycling of the sorbent material. Li and colleagues reported ( $\mathrm{Li}$ et al., 2009b) that the use of the system containing the salt silver tetrafluoroborate along with methylimidazolium hexafluorophosphate ionic liquid covalently supported on silica $\left(\mathrm{AgBF}_{4} / \mathrm{SiO}_{2} \cdot\left[\mathrm{Im}^{+}\right]\left[\mathrm{PF}_{6}{ }_{6}\right]\right)$ resulted in shorter processing times, higher extraction selectivity, and better recyclability in 
comparison with traditional sorbents and reduction in the oxidative instability of the resulting biodiesel. Ionic liquids were also tested for extraction of excess glycerol from biodiesel using a mixture of quaternary ammonium salts with glycerol to form an ionic liquid presenting Lewis basicity, as shown by Abbott et al. (2007) and Hayyan et al. (2010).

\section{TRANSESTERIFICATION WITH IONIC LIQUIDS}

Despite the existence of studies such as those cited above, which use ionic liquids in biodiesel purification or in the conversion of residues from biodiesel production to value-added products, the vast majority of studies focus on the use of ionic liquids in the process of oil transesterification, both as support or catalyst. When ionic liquids are used in the transesterification of triglycerides, the formation of a biphasic system at the end of the reaction occurs because the ionic liquid, insoluble in the organic phase, remains in the aqueous phase along with alcohol, the catalyst used (when it is the case) and glycerol produced during the reaction. The organic phase consists almost entirely of biodiesel. One of the advantages of these systems is the solubility presented by glycerol in a mixture of ionic liquid with methanol (Gamba et al., 2008). Thus, glycerol is removed from the transesterification reaction and the equilibrium is shifted to product formation, increasing the reaction yield. The ionic liquid/alcohol phase containing glycerol should be rinsed with water for 3 to 4 cycles to separate glycerol, which is then isolated in high purity (Dupont et al., 2009). Comparatively, glycerol isolated from the traditional acidic or alkaline catalysis requires several purification steps to achieve similar purity.

\section{Ionic Liquids as Supports}

Ionic liquids are generally divided into two broad classes, one based on chlorometallate anions such as heptachlorodialuminate $\left(\left[\mathrm{Al}_{2} \mathrm{Cl}_{7}\right]^{-}\right)$and the other based on anions not containing metals, such as hexafluorophosphate $\left(\left[\mathrm{PF}_{6}\right]^{-}\right)$. Long et al. (2010) prepared an ionic liquid presenting Lewis acidity formed by choline chloride: $x \mathrm{ZnCl}_{2}$ (where $x$ represents the molar ratio), and claim that this ionic liquid has low cost, good stability against moisture and can be used under mild reaction conditions for transesterification of soybean oil to biodiesel. However the yield, 54.5\% conversion after 72 hours at $70^{\circ} \mathrm{C}$, was not ideal and the separation of biodiesel and soybean oil in the final step was complicated. The transesterification reaction was performed in media with and without moisture (under nitrogen atmosphere), and the biodiesel yield remained practically unchanged, proving that this catalytic system is not sensitive to moisture. Despite this advantage, it would be necessary to improve the catalyst acidity as well as the extraction of glycerol from the ionic liquid, which for this system was difficult and costly.

Chlorometallate-based ionic liquids were also studied as immobilizers for metal compounds such as zinc and tin complexes, which are active catalyst precursors for the transesterification of vegetable oils. Studies show that zinc and tin complexes are more active than traditional catalysts in comparable acid or basic conditions (Abreu et al., 2004). The disadvantage of using these complexes is the difficult recovery and reuse of catalysts, which are dissolved in the reaction medium. Considering this disadvantage, the immobilization of metal complexes in ionic liquids has been studied, especially in those with Lewis acidity. The complex [Sn(3-hydroxy-2methyl-4-pyrone $)_{2}\left(\mathrm{H}_{2} \mathrm{O}\right)_{2}$ ] was immobilized by DaSilveira Neto et al. (2007) in 1-n-butyl-3methylimidazolium tetrachloroindate ([BMI] $\left[\mathrm{InCl}_{4}\right]$ ) and the authors claim that the biphasic catalytic system is effective for producing biodiesel from alcoholysis of soybean oil. Moreover, this paper presents a possible mechanism for the transesterification using this catalytic system. However, this system has disadvantages such as low yields and low activity after recovery of the catalyst. The same tin complex had been immobilized by Abreu et al. (2005) in 1-n-butyl-3-methylimidazolium hexafluorophosphate $\left([\mathrm{BMI}]\left[\mathrm{PF}_{6}\right]\right)$ and also presented inefficiency regarding its reuse. The system formed between the metal complex and ionic liquid was supported on an ion exchange resin and its catalytic activity was maintained, but the reuse of the catalyst was not possible, according to the authors, due to the occurrence of leaching from the ionic catalyst phase.

A successful example of the use of chlorometallate ionic liquids was published by Liang et al. (2009), reporting the synthesis of biodiesel from soybean oil. The catalyst triethylammonium chloroaluminate $\left(\left[\mathrm{Et}_{3} \mathrm{NH}\right] \mathrm{Cl} / \mathrm{AlCl}_{3}\right)$ with an $\mathrm{AlCl}_{3}$ mole fraction of 0.7 showed $98.5 \%$ conversion of soybean oil after 9 hours of reaction at $70^{\circ} \mathrm{C}$ with a methanol:oil ratio of 12:1. The advantages of this method are ease of operation, low cost of catalyst used, high yields, lack of saponification and reusability, because the system could be used six 
times without a significant change in yields obtained. In order to evaluate the efficiency of the synthesized catalyst, the authors conducted a study comparing the catalytic activities of this ionic liquid with traditionally used homogeneous acid catalysts, such as sulfuric acid and phosphoric acid. Taking into account the economic and environmental factors and the increase of production scale, the authors claim that this new catalyst has advantages over traditional catalysts. However, the authors did not present studies of the contamination risks that might arise from the use of these chlorometallate based catalysts, since ionic liquids presenting Lewis acidity or containing metal complexes can lead to metal residues. Furthermore, ionic liquids containing aluminum (III) chloride may be unstable in alcoholic solution, releasing $\mathrm{HCl}$ (Earle et al., 2009).

A possible solution to overcome these risk factors may be the use of ionic liquids prepared without the addition of metal anions in its structure which can be used as supports for catalysts traditionally used. Lapis et al. (2008) published a study in which they performed the immobilization of traditional acidic and alkaline catalysts such as dilute $\mathrm{H}_{2} \mathrm{SO}_{4}$ and $\mathrm{K}_{2} \mathrm{CO}_{3}$ in ionic liquids with the objective of producing biodiesel. The ionic liquids tested were $[\mathrm{BMI}]\left[\mathrm{NTf}_{2}\right],[\mathrm{BMI}]\left[\mathrm{BF}_{4}\right]$ and $[\mathrm{BMI}]\left[\mathrm{PF}_{6}\right]$ and the best result was observed when the organic salt used was $[\mathrm{BMI}]\left[\mathrm{NTf}_{2}\right]$, presenting $98 \%$ yield for the transesterification of soybean oil and high purity of the biodiesel produced. As glycerol is removed from the organic phase during the process, the reaction equilibrium is shifted towards the product formation, increasing the reaction yield. The aqueous phase is then washed to separate the glycerol, which was isolated with high purity (>98\%). This process employed simple purification steps to recover the catalyst and glycerol and the catalytic system can be used at least six times without loss of efficiency.

Ionic liquids based on 1- $n$-butyl-3-methylimidazolium were also studied by Elsheikh et al. (2011) for esterification of free fatty acids present in crude palm oil. The crude palm oil had a high concentration of free fatty acids, so the authors developed a catalytic process in two steps, where initially three ionic liquids with Brønsted acidity were tested for their catalytic efficiency regarding free fatty acid esterification. The 1- $n$-butyl-3-methylimidazolium hydrogensulfate ionic liquid ([BMI] $\left[\mathrm{HSO}_{4}\right]$ ), which possessed the longest carbon chain structure among the salts tested, showed the best results. In the second step, $\mathrm{KOH}$ was added to the medium to catalyze the transesterification of triglycerides with methanol. The reaction was completed in 3 hours and led to a $98.4 \%$ yield of biodiesel. This study also presents an analysis of the influence of varying temperature, time, stirring rate and alcohol and catalyst proportion in the conversion of vegetable oil to biodiesel. A great advantage of this system is the possibility of crude oil esterification and transesterification without the need for costly and time-consuming steps of pretreatment prior to biodiesel production.

\section{Bronsted Acidic Ionic Liquids}

Besides their use as solvents, ionic liquids can be used as single catalysts in the processes of biodiesel production, either by esterification or transesterification, provided that some ionic liquids present Brønsted acidity or basicity. This approach aims to facilitate recovery and to prevent the risk of biodiesel contamination by free catalyst molecules. A study published by Zhang et al. (2009) showed the preparation of ionic liquids containing imidazolium and pyrrolidonium groups and compares the efficiency of these catalysts with Brønsted acidity in biodiesel production, especially from long chain free fatty acids or their mixtures. N-Methyl-2-pyrrolidonium methanesulfonate ([NMP] $\left[\mathrm{CH}_{3} \mathrm{SO}_{3}\right]$, Figure 5 (i)) presented the best catalytic behavior, showing good catalytic performance and good reusability under mild conditions and without the addition of organic solvents. The authors obtained conversion values such as $95.3 \%$ for oleic acid esterification after 8 hours at $70^{\circ} \mathrm{C}$, and this system could be reused eight times, maintaining the conversion above $90 \%$. An interesting feature of this catalyst is its versatility. According to the authors of this study, [NMP] $\left[\mathrm{CH}_{3} \mathrm{SO}_{3}\right]$ was able to convert a wide range of free fatty acids to alkyl esters with conversion efficiencies from 93.6 to $95.3 \%$. Comparing these pyrrolidone-based ionic liquids with traditional acid catalysts, the conversions obtained for the ionic liquids were near or above the conversion values obtained for the conventional catalysts when the reaction was performed at $70^{\circ} \mathrm{C}$.

Cottonseed oil transesterification to biodiesel with methanol was investigated by $\mathrm{Wu}$ et al. (2007) using various Brønsted acidic ionic liquids containing an alkyl chain and a sulfonic acid group. These ionic liquids were composed 1- $n$-butyl-3methylimidazolium or 1-butylpyridinium cations and the ionic liquid 1-(4-sulfonic acid) butylpyridinium hydrogensulfate ([BSPy][ $\left.\mathrm{HSO}_{4}\right]$, Figure 5 (ii)), which presented the higher Brønsted acidity, was the best catalyst. Fatty acid methyl esters were obtained with $92 \%$ yield after 5 hours of reaction at $170^{\circ} \mathrm{C}$, using 12 equivalents of methanol. The authors 
compared the efficiency of a catalytic system containing concentrated sulfuric acid with the system using the ionic liquid and observed that, after $2 \mathrm{~h}$ of reaction with $\mathrm{H}_{2} \mathrm{SO}_{4}$, this traditional system showed a $69 \%$ yield of biodiesel, while the ionic liquid showed a $65 \%$ conversion, meaning that the catalytic activity of this ionic liquid is close to that of the conventional catalyst. Therefore, considering the benefits to the environment, the authors suggest that the ionic liquid would be a more suitable catalyst for the transesterification reaction. This catalyst was used by the same group in a study published by Han et al. (2009) for the production of biodiesel from oils with high concentrations of free fatty acids. The catalyst performance was better at high temperatures and had a yield of $93.5 \%$ of biodiesel production after 4 hours at $170^{\circ} \mathrm{C}$. The ionic liquid could be reused at least nine times with a slight decrease in biodiesel yield. Ionic liquids containing pyridine rings were studied by $\mathrm{Li}$ et al. (2010) as catalysts for esterification and transesterification of Jatropha oil, which presents a high content of free fatty acids. The ionic liquid 1-(4-sulfonic acid) butilpyridinium trifluoromethanesulfonate ([BSPy] $\left[\mathrm{CF}_{3} \mathrm{SO}_{3}\right]$, Figure 5 (iii)) showed the best conversion, resulting in a $92 \%$ biodiesel yield when the reaction was left at $100^{\circ} \mathrm{C}$ for 5 hours using 10 equivalents of alcohol. The product was easily separated from the catalytic system and the ionic liquid maintained its catalytic activity virtually unchanged even after seven reuses.
The ionic liquids cited so far have only one acidic functionality, but currently salts containing several acidic groups are being studied and have shown good results when used in biodiesel production. Fang et al. (2011) synthesized an ionic liquid containing two dialkylsulfonic acid groups with acyclic amines, varying the hydrocarbon chain size between the two nitrogen atoms, as shown in Figure 6 (i). These catalysts were used for the esterification of free fatty acids at $70^{\circ} \mathrm{C}$ for 6 hours, with a yield of 93 to $96 \%$ biodiesel. The product was separated from the biphasic catalytic system through liquid/liquid extraction at room temperature and, after removal of water under vacuum, the catalyst could be reused for at least six times, with the yield decreasing only $3 \%$. According to this study, these dicationic catalysts showed a higher conversion of free fatty acids to biodiesel when compared to traditional catalysts and to monoacid ionic liquids. Liang and Yang (2010) described the synthesis of an ionic liquid presenting a rather interesting structure (Figure 6 (ii)) containing four acid groups. This ionic liquid, according to the authors, is highly resistant to water and to acidic conditions, and the results showed a biodiesel yield above $98 \%$ for the transesterification of rapeseed oil after 7 hours at $70^{\circ} \mathrm{C}$. The four acid groups led to a high catalytic activity for biodiesel synthesis and its high polarity makes it simple to recycle the catalyst. After the reaction, the catalyst was recovered by centrifugation and reused without loss of catalytic efficiency, even after 10 cycles.

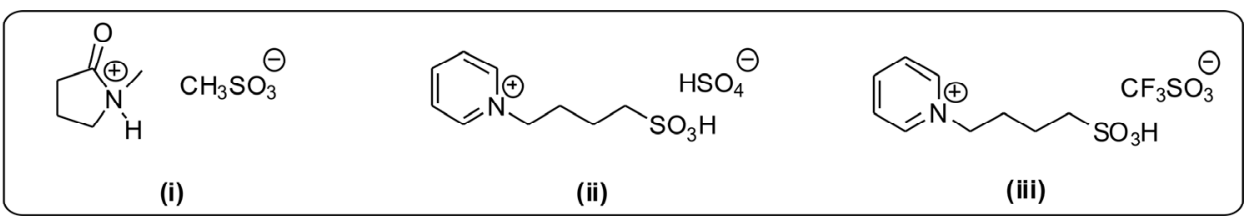

Figure 5: Structure of $[\mathrm{NMP}]\left[\mathrm{CH}_{3} \mathrm{SO}_{3}\right]$ (i), $[\mathrm{BSPy}]\left[\mathrm{HSO}_{4}\right]$ (ii) and $[\mathrm{BSPy}]\left[\mathrm{CF}_{3} \mathrm{SO}_{3}\right]$ (iii) ionic liquids.

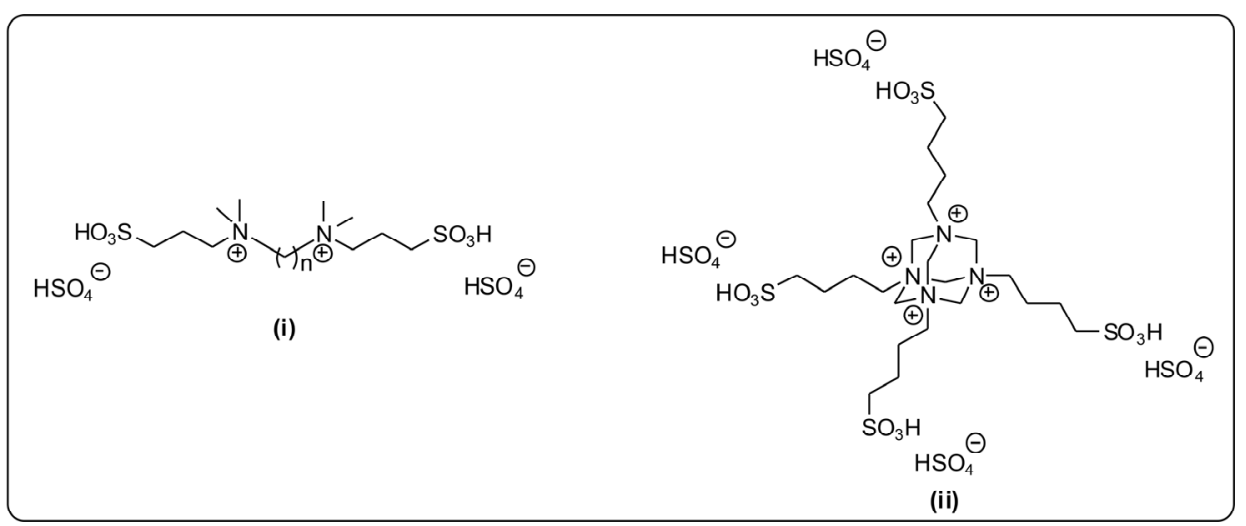

Figure 6: Catalysts used for biodiesel synthesis from free fatty acids (i) and triglycerides (ii) present in rapeseed oil. 


\section{Brønsted Basic Ionic Liquids}

As shown above, there are many examples of ionic liquids with Brønsted acidity that perform esterifications and transesterifications of vegetable oils and animal fats. Studies involving ionic liquids presenting Brønsted basicity for the same purpose, in turn, are rare in the literature. A successful example of this case was described by Liang et al. (2010), who prepared five binuclear ionic liquids containing imidazolium groups that were used as catalysts in the preparation of biodiesel through cottonseed oil transesterification. The best results were obtained for bis-(3-methyl-1-imidazolium)-ethylene dihydroxide $\left(\mathrm{IMC}_{2} \mathrm{OH}\right.$, Figure 7) as catalyst. This paper also presents a study of variables such as catalyst dosage, reaction time, temperature and molar ratio of alcohol for biodiesel preparation. The best biodiesel yield was $98.5 \%$, obtained after 4 hours of reaction at $55^{\circ} \mathrm{C}, 0.4 \%$ catalyst and 12 equivalents of methanol to cottonseed oil. This ionic liquid was recycled seven times and still resulted in $96.2 \%$ conversion, showing no decrease in selectivity.

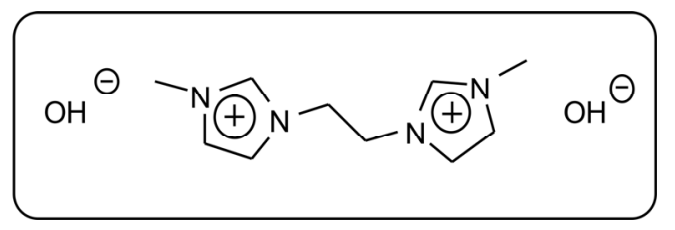

Figure 7: Structure of bis-(3-methyl-1-imidazolium)ethylene dihydroxyl ionic liquid

\section{Ionic Liquids as Supports for Enzymatic Catalysis}

As a final part of this section, we discuss here studies found in the literature successfully applying ionic liquids as enzymatic support, creating a catalytic system which can be used in oil transesterification to biodiesel. Biocatalysis in ionic liquids was first reported in Cull et al. (2000) and Lau et al. (2000) and studies that deal with this theme claim that these systems show a higher selectivity, higher rate and greater enzyme stability. In biodiesel production, the support of enzymes in ionic liquids has been developed aiming to overcome problems associated with conventional enzymatic transesterification, such as enzyme deactivation by some alcohols, particularly methanol, and blockage of active sites of the enzyme by glycerol, which decreases their activity and inhibits the reuse of the biocatalyst. Due to these disadvantages, enzymes, especially lipases, are not applied on an industrial scale, although presenting high catalytic activity for transesterification of triglycerides under mild reaction conditions.

Ha et al. (2007) exemplifies this application and demonstrates the methanolysis of soybean oil catalyzed by lipase in 23 different ionic liquids. The highest yield of biodiesel obtained was $80 \%$ after 12 hours of reaction at $50^{\circ} \mathrm{C}$ with four equivalents of methanol in the ionic liquid 1-ethyl-3-methylimidazolium trifluoromethanosulfonate $\left([\mathrm{Emim}]\left[\mathrm{CF}_{3} \mathrm{SO}_{3}\right]\right)$. The authors claim that this is the first study demonstrating the potential use of ionic liquids as reaction medium for the production of biodiesel catalyzed by lipase. In the study published by Gamba et al. (2008), the lipase was supported in 1-n-butyl-3-methylimidazolium bis $\{$ (trifluoromethyl)sulfonyl $\}$ amide ionic liquid ([BMI] $\left.\left[\mathrm{NTf}_{2}\right]\right)$ and used for biodiesel production by alcoholysis of soybean oil. This reaction can be performed at room temperature in the presence of water (as long as controlled), without the use of organic solvents and using several alcohols (including isoamyl alcohol). The authors mention that water addition is necessary to improve the reaction rate and to increase the rate of oil hydrolysis, resulting in a fatty acid that is converted to its corresponding ester faster than through the transesterification route. The best yield of biodiesel was obtained at $30^{\circ} \mathrm{C}$ and 48 hours of reaction, resulting in $96 \%$ conversion. This high conversion value is partly due to the adsorption of glycerol onto the ionic liquid support, shifting the reaction equilibrium towards the products. The biodiesel produced is recovered by simple decantation and the catalyst system can be reused at least four times without loss of catalytic activity and selectivity. Glycerol is washed and recovered with high purity.

Another example of ionic liquids containing a 1-n-butyl-3-methylimidazolium cation used for the production of biodiesel by transesterification is found in the study published by Ruzich and Bassi (2010). The authors used methyl acetate and $[\mathrm{BMI}]\left[\mathrm{PF}_{6}\right]$ ionic liquid as co-solvent in a lipasecatalyzed transesterification. The ionic liquid was used in this system in order to improve lipase activity and stability, while methyl acetate acts as an acyl acceptor and is used to prevent the deactivation of the enzyme, because, instead of glycerol, the transesterification reaction forms triacetylglicerol, which does not inhibit or denature the lipase. Despite the absence of enzymatic denaturation, removal of the byproduct triacetylglicerol is a disadvantage because the phase separation is not appropriate. Yang et al. (2010) studied the hydrolytic activity and transesterification performance of lipase in the same ionic liquid, as well as in organic solvents like 
hexane. This enzyme has an enhanced activity in the presence of $[\mathrm{BMI}]\left[\mathrm{PF}_{6}\right]$ ionic liquid when compared with its activity in hexane. For example, the initial rate of p-nitrophenyl palmitate hydrolysis catalyzed by this system was increased 12 times in the ionic liquid. Corn oil transesterification with this catalytic system presented, after 25 hours of reaction at $40^{\circ} \mathrm{C}$, a $69.7 \%$ yield of biodiesel in $[\mathrm{BMI}]\left[\mathrm{PF}_{6}\right]$, compared with $19.4 \%, 14 \%$ and $1 \%$ obtained in $t$-butanol, hexane and solvent-free system, respectively.

\section{IONIC LIQUID COSTS}

Ionic liquids are obviously more expensive than traditional solvents and catalysts used in chemical reactions. Two of the most commonly used ionic liquids are 1- $n$-butyl-3-methylimidazolium tetrafluoroborate $\left([\mathrm{BMI}]\left[\mathrm{BF}_{4}\right]\right)$ and 1-n-butyl-3-methylimidazolium hexafluorophosphate ([BMI] $\left.\left[\mathrm{PF}_{6}\right]\right)$. Currently, 250 grams of these organic salts cost US\$ 493 and US\$ 590, respectively, in suppliers such as Sigma-Aldrich and Acros Organics. The most popular alkaline catalyst used for transesterification of vegetable oils, sodium hydroxide, costs US\$ 20 for 250 grams from the same suppliers, so these ionic liquids would cost about 25 times more than traditional catalysts. An alternative to reduce the cost of these organic salts is to synthesize them, which would reduce the cost of these materials to approximately US\$ 150 and US\$ 205 respectively - again using the prices presented by suppliers such as Sigma-Aldrich and Acros Organics - meaning that these materials would be 10 times more expensive than traditional catalysts.

However, not all ionic liquids are expensive. Since we have the possibility to choose the cations and anions composing the ionic liquid, it can present a wide range of costs. For example, cholinebased salts are relatively inexpensive, even from the industrial point of view. Choline chloride costs about US\$ 25 (250 grams), but can be bought in 5 kilos bottles for US\$ 273 from traditional suppliers. Holbrey et al. (2002) prepared an easy and efficient low cost ionic liquid containing methyl and ethyl sulfate anions through the reaction of 1-methylimidazolium (US\$ 65 per $250 \mathrm{~g}$ ) with dimethyl sulfate (US\$ 20 per $250 \mathrm{~mL}$ ) and diethylsulfate (US\$ 30 per $250 \mathrm{~mL}$ ), all prices obtained on the Sigma-Aldrich website.

Furthermore, ionic liquids are commonly used in smaller quantities than traditional catalysts and can be reused in most applications. If we are able to reuse these catalysts at least 10 to 20 times, synthesized ionic liquids would represent the same cost per cycle, or can be even cheaper than conventional catalysts. Therefore, the two factors that will lead to a decision on the feasibility of largescale ionic liquid systems are the ability to reuse the catalysts without activity decrease and attainment of efficient product separation without contamination by the ionic liquid (Plechkova and Seddon, 2008).

\section{CONCLUSIONS}

The studies cited above demonstrate that the use of ionic liquids in biodiesel production is a promising alternative for efficient preparation of biofuels. These compounds have great potential due to the ease of product isolation from the reaction, the possibility of reusing the catalyst and the low risk of environment contamination. As this topic of research is relatively new, there are few studies that focus on the study of biodiesel production using ionic liquids and the lack of complete physical parameters such as conductivity and viscosity are serious disadvantages for the industrial application of ionic liquids at the moment. Furthermore, there are additional challenges that need to be explored, such as reducing costs and increasing ionic liquids reusability. Today, ionic liquids still have a higher cost compared to traditional catalysts. However, it should be taken into account that the higher the number of reuses of these catalysts, the lower the cost of the process. Therefore, studies that focus on the reduction of the production costs of these ionic liquids and their reuse would increase the feasibility of using this system. Among the cited ionic liquids, we consider that salts with Brønsted acidity or basicity are especially interesting because, in addition to a low risk of environmental contamination, they present high conversion yields of vegetable oils and animal fats to biodiesel in a short time with mild reaction conditions. In addition, Brønsted acidic ionic liquids can be used in the conversion of both free fatty acids and triglycerides to biodiesel with no need of pretreatment of the oil for moisture removal. This feature facilitates biodiesel production and reduces process costs, making them promising use in the production of biodiesel.

\section{REFERENCES}

Abbott, A. P., Cullis, P. M., Gibson, M. J., Harris, R. C., Raven, E., Extraction of glycerol from biodiesel into a eutectic based ionic liquid. Green Chemistry, 9, 868-872 (2007). 
Abreu, F. R., Lima, D. G., Hamú, E. H., Wolf, C., Suarez, P. A. Z., Utilization of metal complexes as catalysts in the transesterification of Brazilian vegetable oils with different alcohols. Journal of Molecular Catalysis A-Chemical, 209, 29-33 (2004).

Abreu, F. R., Alves, M. B., Macêdo, C. C. S., Zara, L. F., Suarez, A. Z., New multi-phase catalytic systems based on tin compounds active for vegetable oil transesterification reaction. Journal of Molecular Catalysis A-Chemical, 227, 263-267 (2005).

Anderson, J. L., Armstrong, D. W., Wei, G. -T., Ionic liquids in analytical chemistry. Analytical Chemistry, 78, No. 9, 2892-2902 (2006).

Boon, J. A., Levisky, J. A., Pflug, J. L., Wilkes, J. S., Friedel-Crafts reactions in ambient-temperature molten salts. Journal of Organic Chemistry, 51, No. 4, 480-483 (1986).

Cassol, C. C., Eberling, G., Ferrera, B., Dupont, J., A simple and practical method for the preparation and purity determination of halide-free imidazolium ionic liquids. Advanced Synthesis \& Catalysis, 348, 243-248 (2006).

Cull, S. G., Holbrey, J. D., Vargas-Mora, V., Seddon, K. R., Lye, G. J., Room-temperature ionic liquids as replacements for organic solvents in multiphase bioprocess operations. Biotechnology and Bioengineering, 69, No. 2, 227-233 (2000).

D'anna, F., Frenna, V., Noto, R., Pace, V., Spinelli, D., Study of aromatic nucleophilic substitution with amines on nitriophenes in room-temperature ionic liquids: Are the different effects on the behavior of para-like and ortho-like isomers on going from conventional solvents to roomtemperature ionic liquids related to solvation effects? Journal of Organic Chemistry, 71, 51445150 (2006).

DaSilveira Neto, B. A., Alves, M. B., Lapis, A. A. M., Nachtigall, F. M., Eberlin, M. N., Dupont, J., Suarez, P. A. Z., 1-n-butyl-3-methylimidazolium tetrachloro-indate $\left(\mathrm{BMI} \cdot \mathrm{InCl}_{4}\right)$ as a media for the synthesis of biodiesel from vegetable oils. Journal of Catalysis, 249, 154-161 (2007).

Dupont, J., Suarez, P. A. Z., Meneghetti, M. R., Meneghetti, S. M. P., Catalytic production of biodiesel and diesel-like hydrocarbons from triglycerides. Energy \& Environmental Science, 2, 1258-1265 (2009).

Earle, M. J., Seddon, K. R., Ionic liquids. Green solvents for the future. Pure and Applied Chemistry, 72, No. 7, 1391-1398 (2000).

Earle, M. J., Plechkova, N. V., Seddon, K. R., Green synthesis of biodiesel using ionic liquids. Pure and Applied Chemistry, 81, No. 11, 2045-2057 (2009).
Elsheikh, Y. A., Man, Z., Bustam, M. A., Yusup, S., Wilfred, C. D., Bronted imidazolium ionic liquids: Synthesis and comparison of their catalytic activities as pre-catalyst for biodiesel production through two stage process. Energy Conversion and Management, 52, 804-809 (2011).

Fang, D., Yang, J., Jiao, C., Dicationic ionic liquids as environmentally benign catalysts for biodiesel synthesis. ACS Catalysis, 1, No. 1, $42-47$ (2011).

Fischer, T., Sethi, A., Welton, T., Woolf, J., DielsAlder reactions in room-temperature ionic liquids. Tetrahedron Letters, 40, No. 4, 793-796 (1999).

Forbes, D. C., Law, A. M., Morrison, D. W., The Knoevenagel reaction: analysis and recycling of the ionic liquid medium. Tetrahedron Letters, 47, No. 11, 1699-1703 (2006).

Gamba, M., Lapis, A. A. M., Dupont, J., Supported ionic liquid enzymatic catalysis for the production of biodiesel. Advanced Synthesis \& Catalysis, 350, No. 1, 160-164 (2008).

Ha, S. H., Lan, M. N., Lee, S. H., Hwang, S. M., Koo, Y. -M., Lipase-catalyzed biodiesel production from soybean oil in ionic liquids. Enzyme and Microbial Technology, 41, No. 4, 480-483 (2007).

Han, M., Yi, W., Wu, Q., Liu, Y., Hong, Y., Wang, D., Preparation of biodiesel from waste oils catalysed by a Bronsted acidic ionic liquid. Bioresource Technology, 100, No. 7, 2308-2310 (2009).

Hayyan, M., Mjalli, F. S., Hashim, M. A., Alnashef, I. M., A novel technique for separating glycerine from palm oil-based biodiesel using ionic liquids. Fuel Processing Technology, 91, No. 1, 116-120 (2010).

He, H., Wang, T., Zhu, S., Continuous production of biodiesel fuel from vegetable oil using supercritical methanol process. Fuel, 86, No. 3, 442-447 (2007).

Holbrey, J. D., Reichert, W. M., Swatloski, R. P., Broker, G. A., Pitner, W. R., Seddon, K. R., Rogers, R. D., Efficient, halide free synthesis of new, low cost ionic liquids: 1,3-dialkylimidazolium salts containing methyl- and ethyl-sulfate anions. Green Chemistry, 4, 407-413 (2002).

Iso, M., Chen, B., Eguchi, M., Kudo, T., Shrestha, S., Production of biodiesel fuel from triglycerides and alcohol using immobilized lipase. Journal of Molecular Catalysis B-Enzymatic, 16, No. 1, 53-58 (2001).

Kubisa, P., Ionic liquids as solvents for polymerization processes - Progress and challenges. Progress in Polymer Science, 34, No. 12, 1333-1347 (2009).

Lapis, A. A. M., Oliveira, L. F., Neto, B. A. D., Dupont, J., Ionic liquid supported acid/base- 
catalyzed production of biodiesel. ChemSusChem., 1, No. 8-9, 759-762 (2008).

Lau, R. M., Rantwijk, F., Seddon, K. R., Sheldon, R. A., Lipase-catalyzed reactions in ionic liquids. Organic Letters, 2, No. 26, 4189-4191 (2000).

Laus, G., Bentivoglio, G., Schottenberger, H., Kahlenberg, V., Kopacka, H., Roder, T., Sixta, H., Ionic liquids: Current developments, potential and drawbacks for industrial applications. Lenzinger Berichte, 84, 71-85 (2005).

Li, K. -X., Chen, L., Yan, Z. -C., Wang, H. -L., Application of pyridinium ionic liquid as a recyclable catalyst for acid-catalyzed transesterification of Jatropha oil. Catalysis Letters, 139, 151-156 (2010).

Li, L., Yu, S. -T., Xie, C. -X., Liu, F. -S., Li, H. -J., Synthesis of glycerol triacetate using functionalized ionic liquid as catalyst. Journal of Chemical Technology and Biotechnology, 84, No. 11, 1649-1652 (2009a).

Li, M., Pham, P. J., Wang, T., Pittman, C. U., Li, T., Solid phase extraction and enrichment of essential fatty acid methyl esters from soyderived biodiesel by novel П-complexing sorbents. Bioresource Technology, 100, No. 24, 6385-6390 (2009b).

Li, Z., Jia, Z., Luan, Y., Mu, T., Ionic liquids for synthesis of inorganic nanomaterials. Current Opinion in Solid State \& Materials Science, 12, No. 1, 1-8 (2008).

Liang, J. -H., Ren, X. -Q., Wang, J. -T., Jinag, M., Li, Z. -J., Preparation of biodiesel by transesterification from cottonseed oil using the basic dication ionic liquids as catalysts. Journal of Fuel Chemistry and Technology, 38, No. 3, 275-280 (2010).

Liang, X., Gong, G., Wu, H., Yang, J., Highly efficient procedure for the synthesis of biodiesel from soybean oil using chloroaluminate ionic liquid as catalyst. Fuel, 88, No. 4, 613-616 (2009).

Liang, X., Yang, J., Synthesis of a novel multi$\mathrm{SO} 3 \mathrm{H}$ functionalized ionic liquid and its catalytic activities for biodiesel synthesis. Green Chemistry, 12, 201-204 (2010).

Liu, X., Piao, X., Wang, Y., Zhu, S., Calcium ethoxide as a solid base catalyst for the transesterification of soybean oil to biodiesel. Energy \& Fuels, 22, No. 2, 1313-1317 (2008).

Long, T., Deng, Y., Gan, S., Chen, J., Application of choline chloride. $x \mathrm{ZnCl}_{2}$ ionic liquids for preparation of biodiesel. Chinese Journal of Chemical Engineering, 18, No. 2, 322-327 (2010).

Ma, F. and Hanna, M. A., Biodiesel production: a review. Bioresource Technology, 70, No. 1, 1-15 (1999).
Marchetti, J. M., Miguel, V. U., Errazu, A. F., Possible methods for biodiesel production. Renewable \& Sustainable Energy Reviews, 11, No. 6, 1300-1311 (2007).

Marsh, K. N., Boxall, J. A., Lichtenthaer, R., Room temperature ionic liquids and their mixtures - a review. Fluid Phase Equilibria, 219, No. 1, 93-98 (2004).

Plechkova, N. V., Seddon, K. R., Applications of ionic liquids in the chemical industry. Chemical Society Reviews, 37, No. 1, 123-150 (2008).

Puna, J. F., Gomes, J. F., Correia, M. J. N., Dias, A. P. S., Bordado, J. C., Advances on the development of novel heterogeneous catalysts for transesterification of triglycerides in biodiesel. Fuel, 89, No. 11, 3602-3606 (2010).

Ranganathan, S. V., Narasimhan, S. L., Muthukumar, $\mathrm{K}$., An overview of enzymatic production of biodiesel. Bioresource Technology, 99, No. 10, 3975-3981 (2008).

Rantwijk, F. and Sheldon, R. A., Biocatalysis in ionic liquids. Chemical Reviews, 107, No. 6, 2757-2785 (2007).

Rogers, R. D., Seddon, K. R., Ionic liquids - Solvents of the future? Science, 302, $792-793$ (2003).

Roosen, C., Muller, P., Greiner, L., Ionic liquids in biotechnology: applications and perspectives for biotransformations. Applied Microbiology and Biotechnology, 81, No. 4, 607-614 (2008).

Ruzich, N. I. and Bassi, A. S., Investigation of lipase-catalized biodiesel production using ionic liquid $[\mathrm{BMIM}]\left[\mathrm{PF}_{6}\right]$ as a co-solvent in $500 \mathrm{~mL}$ jacketed conical and shake flask reactors using triolein or waste canola oil as substrates. Energy \& Fuels, 24, No. 5, 3214-3222 (2010).

Schuchardt, U., Sercheli, R., Vargas, R. M., Transesterification of vegetable oils: A review. Journal of the Brazilian Chemical Society, 9, No. 3, 199-210 (1998).

Scifinder: Scientific publications database. Available at: <https://origin-scifinder.cas.org $>$. (Accessed in September 12, 2011).

Seddon, K. R., Ionic liquids for clean technology. Journal of Chemical Technology and Biotechnology, 68, No. 4, 351-356 (1997).

Seddon, K. R., Ionic liquids: A taste of the future. Nature Materials, 2, No. 6, 363-365 (2003).

Short, P. L., Out of the ivory tower. Chemical \& Engineering News, 84, No. 17, 15-21 (2006).

Suarez, P. A. Z., Dullius, J. E. L., Einloft, S., Souza, R. F., Dupont, J., The use of new ionic liquids in two-phase catalytic hydrogenation reaction by rhodium complexes. Polyhedron, 15, No. 7, 12171219 (1996). 
Vicente, G., Martínez, M., Aracil, J., Integrated biodiesel production: a comparison of different homogeneous catalysts systems. Bioresource Technology, 92, No. 3, 297-305 (2004).

Welton, T., Room-temperature ionic liquids. Solvents for synthesis and catalysis. Chemical Reviews, 99, No. 9, 2071-2083 (1999).

Welton, T., Ionic liquids in catalysis. Coordination Chemistry Reviews, 248, No. 21-24, 2459-2477 (2004).

Wilkes, J. S., Levisky, J. A., Wilson, R. A., Hussey, C. L., Dialkylimidazolium chloroaluminate melts: a new class of room-temperature ionic liquids for electrochemistry, spectroscopy and synthesis. Inorganic Chemistry, 21, No. 3, 1263-1264 (1982).

Wu, Q., Chen, H., Han, M., Wang, D., Wang, J., Transesterification of cottonseed oil catalized by Bronsted acidic ionic liquids. Industrial \&
Engineering Chemistry Research, 46, No. 24, 7955-7960 (2007).

Yang, Z., Zhang, K. -P., Huang, Y., Wang, Z., Both hydrolytic and transesterification activities of Penicillium expansum lipase are significantly enhanced in ionic liquid $[\mathrm{BMIm}]\left[\mathrm{PF}_{6}\right]$. Journal of Molecular Catalalysis B-Enzymatic, 63, 23-30 (2010).

Zhang, L., Xian, M., He, Y., Li, L., Yang, J., Yu, S., $\mathrm{Xu}, \mathrm{X}$., A Bronsted acidic ionic liquid as an efficient and environmentally benign catalyst for biodiesel synthesis from free fatty acids and alcohols. Bioresouce Technology, 100, No. 19, 4368-4373 (2009).

Zheng, S., Kates, M., Dubé, M. A., Mclean, D. D., Acid-catalyzed production of biodiesel from waste frying oil. Biomass \& Bioenergy, 30, No. 3, 267-272 (2006). 